EMBL acts as a service centre, with P3 and $\mathrm{P} 4$ laboratories, outstations using synchrotron light at Hamburg and neutrons at Grenoble, and instrumentation and computer groups at Heidelberg. So it is necessary, EMBL thinking goes, for the staff scientists concerned to pursue the most up to date lines of research, to keep them in touch with the immediate needs of the scientific community. Thus flexibility is a prime goal, and short-term contracts and small groups provide it.

The Danish meeting on EMBL towards the end of next month will consist not only of biologists. There will be representatives of the research councils for natural science, agriculture and medicine, just as there were on the original working party that produced the original report, so it is difficult to predict the outcome. However, whereas that report recommended that the government should foot the $£ 120,000$ EMBL bill, the new report may suggest that a single research council takes the subscription into its own budget. An obstacle may be that at present no Danish biologist works at EMBL, although a computer scientist and some ancillary staff do so.

Robert Walgate

\section{Scientific instruments}

\section{Nature spin-off}

The colour filters supplied with the 3 April issue of Nature have turned out to have an unexpected use. In some laboratories, it seems that the filters are superior to others on the market in the contrast they provide.

Dr R. Zeki of University College London, whose article on colour vision prompted the distribution of the set of three colour filters (Nature 284, 412-421; 1980 ), said last week that he had received a number of comments on the value of the filters, which he had passed on to Polaroid, the manufacturers.

One of those who have found the red filter of particular value is Mr David Owen, a graduate student in the laboratory of $\mathrm{Dr}$ C. Harwood, of the University of Newcastle upon Tyne. One series of experiments is to identify extra-

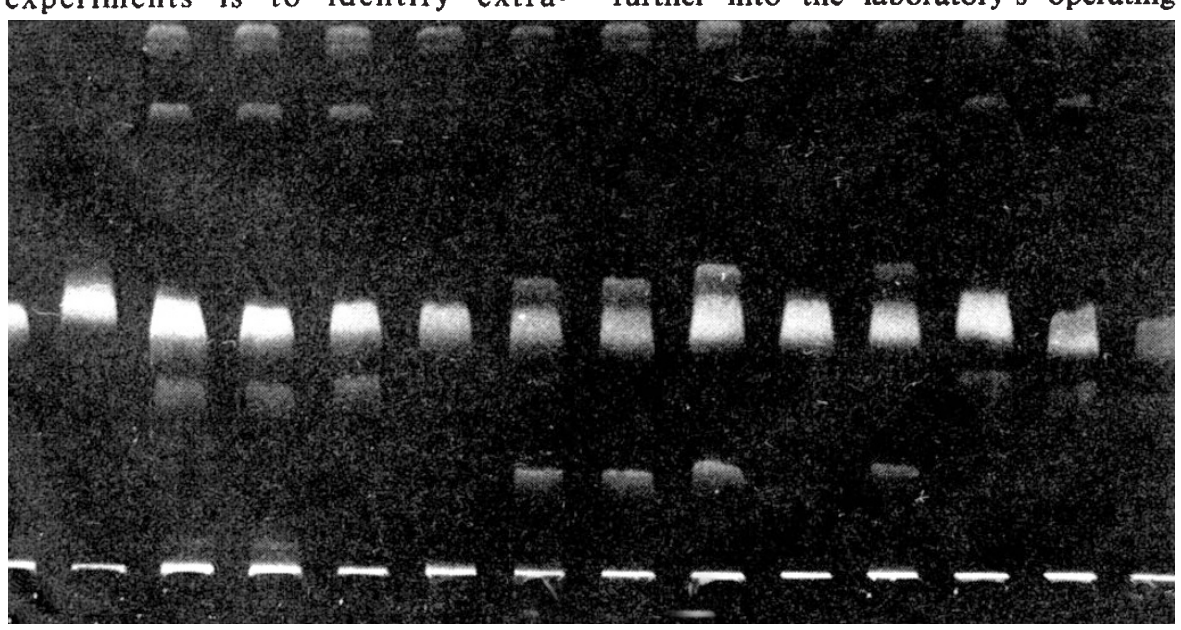

chromosomal genetic elements in bacteria. The procedure is to separate DNA molecules by gel electrophoresis and to make molecules of different classes apparent by treating the gel with a fluorescent dye that binds to DNA.

$\mathrm{Mr}$ Owen explained last week that he had had some trouble finding a suitable filter for photographing the pattern of visible light stimulated by ultraviolet radiation, so he had tried "Dr Zeki's red filter".

"To our surprise", he said, "the resulting photographs were far superior ... in that the DNA bands were clearly visible against a black background". The accompanying illustration is an example of such a photograph, in which the bright central band represents chromosomal DNA and the sidebands DNA from plasmids.

No agreed explanation of this result is available, although it seems likely that the narrowness of the transmission band of the red filter may account for the sharp contrast.

The Polarioid Corporation has apparently developed these filters largely for research purposes. A spokesman for the company said last week that filters with narrow transmission bands should be available from more conventional sources, but that the company might reconsider its decision that its filters would not be put on the market if the demand for them turned out to be sufficient.

\section{High-energy physics}

\section{Trouble ahead}

\section{Washington}

As if bleak budget prospects were not enough, high-energy physicists in the United States are facing another delicate question - what to do about continued difficulties in the development of superconducting magnets for the $400 \times 400$ $\mathrm{GeV}$ accelerator (ISABELLE) now under construction at the Brookhaven National Laboratory on Long Island.

The official line is that a substantial effort must be maintained to resolve the difficulties, even if this means cutting further into the laboratory's operating 